\title{
A comparison between Volumetric Timber Manufacturing Strategies in the UK and mainland Europe
}

\author{
Tsvetomila DUNCHEVA ${ }^{1}$ and Fiona F. BRADLEY ${ }^{2 *}$ \\ ${ }^{1}$ PhD Candidate, Department of Architecture, University of Strathclyde, Glasgow \\ ${ }^{2}$ Senior University Teacher, School of Engineering, University of Glasgow, UK \\ "Corresponding author's e-mail: fiona.bradley@ glasgow.ac.uk
}

\begin{abstract}
The construction sector in the UK is currently being challenged by an urgent need to produce housing. This requirement is within a context of increasingly stringent greenhouse gas emission legislation and tough goals to reduce build time by $50 \%$ and financial cost by $33 \%$ by the year 2025. Many agree that these targets and others relating to build quality and productivity can only be achieved with increased utilisation of Modern Methods of Construction (MMC). This research study proposes that Volumetric Timber construction (VT) is a suitable system for use in the UK, as it can achieve up to $95 \%$ prefabrication in a controlled factory environment combined with rapid onsite construction. There are a variety of VT timber systems on the market, including timber studs, Cross Laminated Timber (CLT) and Structurally Insulated Panel (SIP) structures and a variety of production methods. This paper presents findings from a study comparing four VT manufacturers in the UK and four in mainland Europe. Different design and processing methods have been compared and analysed with respect to production type, offsite components and productivity metrics. The findings demonstrate that there are diverse approaches to efficient VT manufacturing and opportunities for flexibility in the design of products to suit local market conditions.
\end{abstract}

\section{KEYWORDS}

Volumetric timber construction; Modular; Offsite Manufacturing; Productivity;

\section{INTRODUCTION}

In the UK today, there is an urgent requirement to construct approximately 240,000 houses per year in order to alleviate what is being termed the "housing crisis" (de Castella 2015). This significant production and delivery challenge for the industry is being further exacerbated by widely reported skills shortage and legal requirements to adhere to increasingly stringent energy and carbon reduction targets. In addition, the Government has recently set demanding targets for the industry requiring reductions in construction time and cost of 50\% and 33\%, respectively, by the year 2025 (HM Government 2013).

The temperate climate of the UK characterised by relatively high rainfall, frequent high winds and fairly low temperatures in winter can affect construction progress on site at different times of the 
year and as a result, offsite construction, which transfers some processes from site to a controlled factory environment, has been proposed as a potential solution. Offsite or factory based construction has been shown to minimise construction downtime as well as improve quality, reduce waste and improve efficiency (Kamali and Hewage 2016; Miles and Whitehouse 2013) and there has therefore been a recent interest in the UK in examining the potential of Modern Methods of Construction (MMC). One particular form of MMC system is Volumetric Timber construction (VT), a highly prefabricated three dimensional structure in which modules are manufactured and transported to site with a high level of finishing. This system therefore has the potential to optimise and increase the efficiency of construction due to its low carbon, light weight, sustainable and high quality characteristics. Examples of VT modules from 2015 and 2016 are shown in Figure 1.

This VT research study has compared four UK manufacturers and four in mainland Europe, where VT has become more mainstream in recent years. These eight manufacturers have been compared with respect to a number of parameters relating to their operations and processes in particular production type, offsite components and productivity metrics.
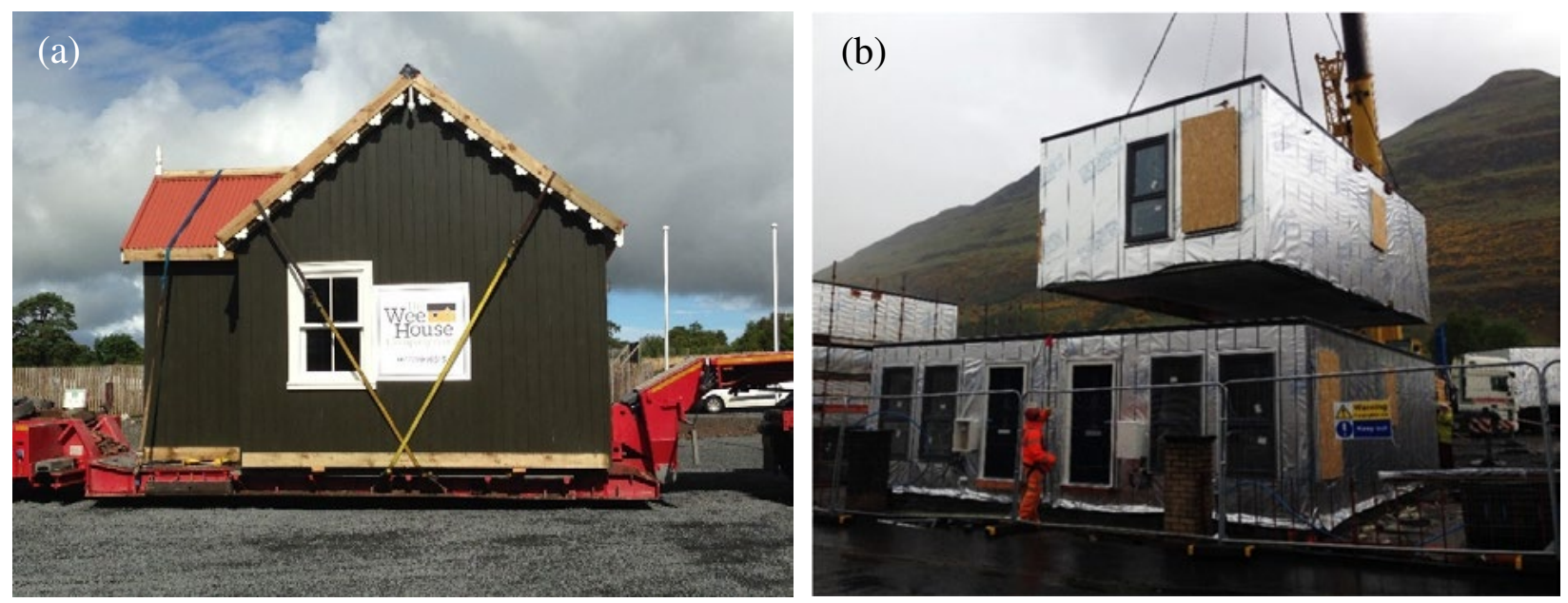

Figure 1. VT module examples: (a) relocation of a one-bedroom house, 2015; (b) construction of two semi-detached two-bedroom houses, 2016. Included with permission from the Wee House Company, Tigh Grian and Link HA.

\section{LITERATURE REVIEW}

A number of different forms of timber MMC have been developed and applied in the UK during the last decade, including open panels, floor cassettes, closed panels, bathroom pods and volumetric (modular) (Hairstans 2015). Of these, VT has the highest level of prefabrication and therefore provides the greatest opportunity to optimise construction due to its use of specialised assembly lines in a factories and implementation of Lean construction (Womack and Jones 2003). Despite this VT advantage, a survey of leading housebuilders across the UK found that twodimensional (less prefabricated) methods of offsite timber frame and floor cassettes were the most widely utilised, whilst volumetric or modular offsite methods were only marginally used (Pan et al. 2005). A similar subsequent study confirmed that the most developed offsite timber systems in the UK in 2008 were open panels ( $£ 528 \mathrm{~m}$ ) with only a negligible output of closed panels (£20m) (Taylor 2010). 
In the last few years, there has been an increase in support for the use of offsite in the UK across all sectors due to the perceived benefits that offsite provides across all three sustainability criteria; namely economic, environmental and societal (Krug and Miles 2013). Selected recent studies on the opportunities and challenges associated with offsite and volumetric construction are summarised in Table 1. A survey conducted last year on UK house builders found that the industry perceived offsite as an enabling driver for housing development, although some concerns were raised relating to the anticipated increased production costs that would be necessary due to the need for new facilities and equipment investment (Homes for Scotland 2015). However, due to its potential for achieving governmental and industry targets, publically available guides to promote MMC have been issued by BuildOffsite to encourage the mainstream implementation of offsite methods of construction within the UK (Hairstans 2015).

Table 1. Main opportunities and challenges associated with offsite and volumetric construction.

\begin{tabular}{lll}
\hline Type & Criteria & Further reading \\
\hline Opportunity & Time savings & (Kamali and Hewage 2016) \\
\hline Opportunity & Cost savings & (Kuittinen 2015) \\
\hline Opportunity & Carbon reduction & (Dodoo et al. 2014; Monahan and Powell 2011) \\
\hline Opportunity & Quality control & (Johnsson and Meiling 2009; Meiling et al. 2015) \\
\hline Opportunity & Waste reduction & (Jaillon et al. 2009; Nahmens and Ikuma 2012) \\
\hline Challenge & Transportation & (Lehmann 2013) \\
\hline Challenge & Site restrictions & (Kamali and Hewage 2016) \\
\hline Challenge & Upfront design & (Kamali and Hewage 2016) \\
\hline
\end{tabular}

\section{METHODOLOGY}

The research method used for this study was a qualitative survey comprising face-to-face interviews and tours of eight VT manufacturing facilities in the UK and mainland Europe. The companies were at different stages of manufacturing development with some just starting to transition from onsite work and open panels to VT, whereas others were established international VT suppliers. The UK participants gave permission to record and transcribe the interviews, whilst hand-written notes were used with the EU participants. The data was tabulated in MS Excel and analysed using a compare and contrast approach. A typical interview duration was between 3 and 8 hours, the longer time period representing two interviews in the EU split over two days each. The research was conducted between the 22 ${ }^{\text {nd }}$ August 2015 and $27^{\text {th }}$ May 2016 and therefore represents a recent overview of the European VT manufacturing industry. It was not possible to collect company-sensitive data about production costs due to confidentiality issues and there was also the potential to miss relevant information due to the fact that only one site visit was conducted per company. However, a structured interview method with identical questions and validation of the results by company representatives were used to try to overcome these constraints.

\section{RESULTS AND DISCUSSION}

\section{Manufacturing process}


Production type. The visited companies can be separated into two main manufacturing systems: factories and workshops. Six companies had moving assembly lines with several stations and their production staff were specialised in one part of the module production. This method was termed a 'factory' scenario in this research, as it embodied the Lean principles of manufacturing used in the motorcar and electronic industries. Two companies operated in a relatively smaller open plan building, where modules were assembled without being moved until their completion and their staff were less specialised. This system is termed a 'workshop' scenario in this research study. The main difference was that in factories, the product was moved between materials and workers, whilst in the workshops materials and workers moved to the products. The factory buildings varied in size from 2,000 $\mathrm{m}^{2}$ to $20,000 \mathrm{~m}^{2}$ and were re-purposed industrial buildings, custom-built in the past and continuously extended or recently custom-built. The results presented in Table 2 capture the variety of approaches to VT production.

Table 2. Factory comparison based on production type.

\begin{tabular}{lcccccccc}
\hline Classification & UK1 & UK2 & UK3 & UK4 & EU1 & EU2 & EU3 & EU4 \\
\hline $\begin{array}{l}\text { Production } \\
\text { type }\end{array}$ & $\mathrm{W}$ & $\mathrm{W}$ & $\mathrm{F}$ & $\mathrm{F}$ & $\mathrm{F}$ & $\mathrm{F}$ & $\mathrm{F}$ & $\mathrm{F}$ \\
\hline Timber system & Stud & $\begin{array}{c}\text { CLT }+ \\
\text { Stud }\end{array}$ & SIP & $\begin{array}{c}\text { I- } \\
\text { beams }\end{array}$ & Stud & $\begin{array}{c}\text { CLT }+ \\
\text { Stud }\end{array}$ & Stud & Stud \\
\hline N lines overall & 1 & 2 & 3 & 2 & 4 & 5 & 4 & 4 \\
\hline N module lines & 1 & 2 & 2 & 2 & 1 & 3 & 2 & 3 \\
\hline CAM & No & No & No & No & Yes & Yes & No & Yes \\
\hline Size estimate & $S$ & $M$ & $L$ & $M$ & $L$ & $L$ & $L$ & $L$ \\
\hline Key: & W=Workshop; F=factory; A=Advanced; S=small; M=medium, L=large; \\
\hline
\end{tabular}

System. A variety of timber systems were used by the companies, with timber stud being the most common. The manufacturers tended to specialise in one timber system each although one company also produced non-timber modules in a different location within their premises. Each VT product was divided into a series of production activities comprising panel framing, insulation, wiring, boarding, module assembly, installation of fittings, fixtures and services, windows, doors and cladding. The timber stud factories had a larger number of manufacturing lines, because they firstly cut the timber studs and sheets to size (L1), secondly assembled closed panels (L2) and finally assembled the panels into modules (L3) as shown in Figure 2.

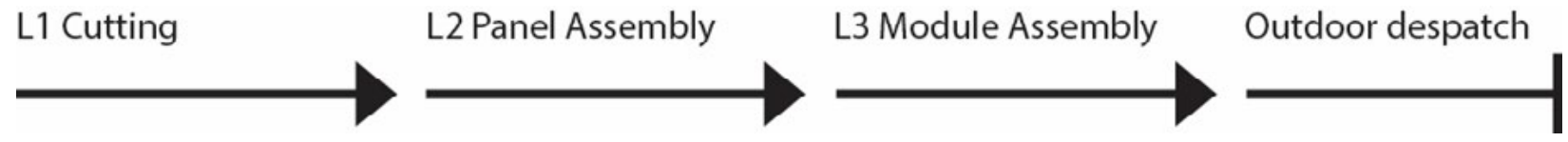

Figure 2. VT production: generalised process flow.

Panels. In-house built panels generally comprised the familiar $600 \mathrm{~mm}$ centre timber stud frame. The largest panel sizes were based on the exterior dimensions of the modules and were in general approximately $(12 \mathrm{~m} \times 3 \mathrm{~m} \times 0.4 \mathrm{~m})$ or $(4 \mathrm{~m} \times 3 \mathrm{~m}$ by $0.4 \mathrm{~m})$. Three manufacturers were flexible with the level of offsite production and provided either open or closed timber panels for projects where VT was not suitable or was not preferred by their clients. Indeed, "flat-pack" versus full 3D 
transportation was sometimes deemed to be more cost-efficient for long distance haulage and VT buildings which included long spanning rooms tended to include flat panels.

The relationship between panel production and module production is one of the greatest challenges to VT implementation due to the culture of the building industry, where unfortunately many decisions are taken on site after construction has started. Some survey participants therefore stated that the development of a mainstream VT industry will be challenged by the current culture of onsite adjustments as well as the commercial environment of an industry with long-established manufacturing plants for offsite 2D panels. This observation confirmed the findings of previous research that existing UK housebuilders are currently reluctant to re-design their house types for offsite systems and therefore continue to utilise traditional onsite methods (Homes for Scotland 2015). The established timber panel manufacturing industry may be a hindrance to VT implementation in the UK, however this could be overcome if the panel manufacturers considered expanding their market by including module assembly lines in their manufacturing processes.

Modules. The sizes of the modules were dictated by transportation restrictions in the specific country although they were generally approximately $(13 \mathrm{~m} \times 4 \mathrm{~m} \times 3.5 \mathrm{~m}$.) The level of offsite completion of the modules was high across all companies; all of the companies' modular products were delivered to site complete with a timber structure, insulation, air tight membranes, doors, windows, finishes, cladding, services, fittings and built-in furniture. The only difference was observed in UK1, who had made a design decision to produce less air tight than possible buildings in favour of producing a 'breathable timber building' and therefore did not include air tight membranes. A comparison between the modular products based on the components included in the factory process is shown in Table 3.

Table 3. Offsite level comparison based on components included in the factory construction.

\begin{tabular}{lcccccccc}
\hline Component & UK1 & UK2 & UK3 & UK4 & EU1 & EU2 & EU3 & EU4 \\
\hline Structure & Yes & Yes & Yes & Yes & Yes & Yes & Yes & Yes \\
\hline Insulation & Yes & Yes & Yes & Yes & Yes & Yes & Yes & Yes \\
\hline Airtight membrane & No & Yes & Yes & Yes & Yes & Yes & Yes & Yes \\
\hline Internal finishes & Yes & Yes & Yes & Yes & Yes & Yes & Yes & Yes \\
\hline Cladding & Yes & Yes & Yes & Yes & Yes & Yes & Yes & Yes \\
\hline Windows & Yes & Yes & Yes & Yes & Yes & Yes & Yes & Yes \\
\hline Doors & Yes & Yes & Yes & Yes & Yes & Yes & Yes & Yes \\
\hline MEP & Yes & Yes & Yes & Yes & Yes & Yes & Yes & Yes \\
\hline Fittings & Yes & Yes & Yes & Yes & Yes & Yes & Yes & Yes \\
\hline Furniture & Yes & Yes & Yes & Yes & Yes & Yes & Yes & Yes \\
\hline Staircase & No & No & Yes & Yes & Yes & Yes & Yes & Yes \\
\hline Roof & No & Yes & No & Yes & No & No & No & No \\
\hline Patio & Yes & No & No & Yes & No & No & No & No \\
\hline Offer panels & No & No & No & Yes & Yes & No & No & Yes \\
\hline & & & & & & & &
\end{tabular}

The variable offsite components tended to be staircases and roofs. These components depended on the contractual arrangements and the specific project design. For example, if the manufacturer was only contracted to fabricate the modules, the site contractor built the roof. Alternatively, if it was found that transporting a prefabricated trussed roof was costlier than constructing one on site, the 
manufacturing teams would build the roof onsite using traditional triangular trusses. Importantly, the companies were flexible with some of the offsite components, such as floor finishes and builtin furniture, as some clients preferred to install these onsite using specialist suppliers or save on costs by doing it themselves.

Automation. The use of Computer Aided Manufacturing (CAM) significantly influenced the surveyed companies' productivity. One example of CAM is the 'nailing bridge' shown in Figure 3, which receives information from a digital file describing the specific nail locations in the appropriate timber panels. The machine nails a timber or plaster board to the frame with automated nail guns that move in three dimensional axes executing the operation in seconds with $\mathrm{mm}$ precision. This procedure reduces time and improves quality compared to manual methods. Other machinery can flip, rotate, cut and sort out materials or components.

The cutting (L1) and panel assembly lines (L2) provided opportunities for CAM, whilst the module assembly lines (L3) tended to be manual in all of the visited manufacturers. The European companies were more inclined to use automation and appeared to have more financial support to invest in equipment and also had an ongoing engagement with process improvement through Research and Development (R\&D). Indeed, in Europe recently established and market leading companies were continuously improving their processes. In contrast, UK R\&D was perceived as only feasible in well-established factories.
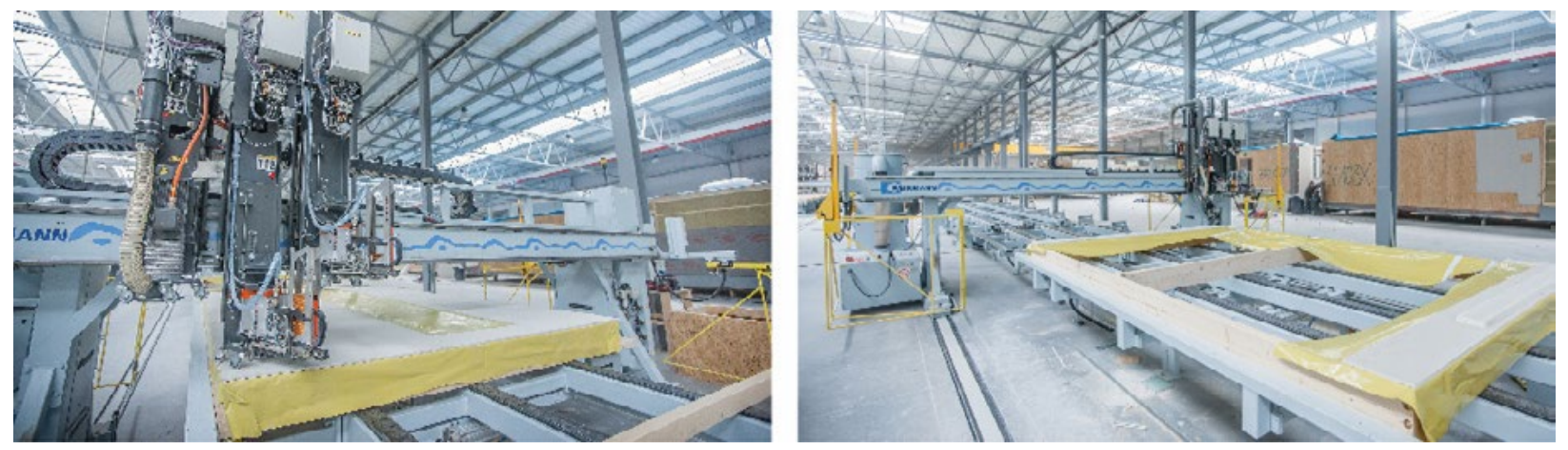

Figure 3. Nailing bridge. Photographs credits: Nordhus. Included with permission.

\section{Productivity}

UK4 were in the process of setting up a factory and their productivity metrics cannot be discussed.

Time. The EU factories could produce more modules per week, or had higher efficiency, compared with the UK, as shown in Table 4. Indeed, the combination of automation, a large production facility and two or more parallel module assembly lines drastically increased the production by up to 19 modules a week. One EU manufacturer for instance stated that their maximum output was 36 modules a week. To put this in context, if an apartment consisted of two modules, this is a production rate of 18 apartments per week. This finding is in line with the conclusions of previous surveys, which have demonstrated the potential of offsite construction to improve the efficiency of housebuilding (Krug and Miles 2013; Miles and Whitehouse 2013).

Five companies stated that they were continuously under pressure to try to maintain efficiency and productivity levels due to the lack of a constant supply of orders and therefore an uneven production schedule of new projects. This meant that sometimes production lines lay empty for 
prolonged periods in between projects or were only partially used when the factories were not working at full capacity. In contrast, the remaining two operating factories had projects planned for the year ahead. This circumstance facilitated higher productivity, but also presented challenges ie there was not always sufficient time to prepare assembly lines and material stocks for subsequent projects in advance of production starts. Sustaining a continuous flow of projects was only possible if developers had made early contact with the manufacturers therefore allowing sufficient lead-in times for architectural design and planning approval before modules were required to be produced. This showed that rapid and sustainable production was possible but dependant on external factors.

Table 4. Factory comparison according to productivity metrics.

\begin{tabular}{lcccccccc}
\hline Metric & UK1 & UK2 & UK3 & UK4 & EU1 & EU2 & EU3 & EU4 \\
\hline $\begin{array}{l}\text { Modules per } \\
\text { week av }(N)\end{array}$ & 1 & 1 & 7 & 2 & 10 & 13 & 20 & 7 \\
\hline $\begin{array}{l}\text { Property sale } \\
\text { price av } \\
\left(G B P / m^{2}\right.\end{array}$ & $£ 1,400$ & $£ 2,000$ & $£ 1,300$ & & $£ 900$ & $£ 2,400$ & $£ 1,200$ & $£ 3,400$ \\
$\begin{array}{l}\left.U S D / m^{2}\right) * \\
\text { Key: av=average; } \mathrm{N}=\text { number; } \mathrm{n} / \mathrm{k}=\text { unknown (under construction); *(Bank of England 2016); }\end{array}$ \\
\hline
\end{tabular}

Property sale price. The level of automation, the size of the factory, the factory layout, the location of the factory, the location of the projects and the number of man-hours all have an effect on the module price. For example, in mainland Europe there was a trend of exporting modules to countries with higher GDPs; this was most noticeably reflected in the final sale prices of EU4. The final property prices for the home buyers, however, were set by the developers and were mainly dictated by geographic location and the local market. The home owners were indeed said to be unaware of the building technology in their properties, but put emphasis on the interior design elements. The internal surface materials and kitchen and bathroom appliance specifications determined the price difference between affordable and high-end housing. For example, in the leisure sector, high quality doors, windows and finishes were specified for hotel rooms, whilst in the affordable homes sector, the leading criteria were energy-efficiency and durability.

Interestingly, there was no direct connection between the level of automation in the factories and the property prices. The factories that had invested in automated production equipment did not inflate the module prices to recoup their investment. Instead they benefited from increased productivity rates; provided that the companies had the capacity to supply a high module output and also provided there was sufficient demand for large, repetitive modular projects such as apartment blocks. A major challenge to increased offsite application in the UK currently voiced however is the perception that VT modules are more expensive than traditional methods of construction because of the requirement for increased automation (Homes for Scotland 2015). This research interestingly demonstrated that the final property prices were determined by the local market rather than by automation. This aligns with the conclusions of (Krug and Miles 2013).

\section{CONCLUSION}

The survey of four UK and four EU VT manufacturers demonstrated that the main opportunity that VT brings to construction is productivity increases. Production processes, timber system 
specifications and use of automation all contribute to efficiency and can be designed to suit local market contexts and company profiles and, if carefully considered, result in efficient manufacturing strategies. The VT products observed during this study were all highly prefabricated and included finishes and services and the level of offsite module completion was seen to be flexible, with the option to accommodate different client requirements. In the "factory" manufacturers, the use of automation enabled generally higher outputs than in the "workshop" manufacturers. Contrary to popular belief, the use of automation was not seen to influence the final property price and importantly, the potential to produce eighteen apartments per week will be appealing for areas with a pressing need for housing. A fine balance has to be maintained however between the facility type, equipment cost, man hour costs, product specification, local context and labour market and international market demand fluctuations.

\section{ACKNOWLEDGEMENTS}

The University of Strathclyde funded this research with an Engineering the Future Studentship. COCIS Edinburgh generously funded the conference travel to the MOC Summit and we sincerely thank the anonymous interviewees for their detailed explanations, for validating the results presented in this paper and for permitting the use of images.

\section{REFERENCES}

Bank of England. (2016). "Daily Spot Exchange rates against Sterling. August 17 2016." Statistical Interactive Database, <http://bit.ly/2bsyBEU> (Jan. 1, 2016).

de Castella, T. (2015). “Why can't the UK build 240,000 houses a year?” BBC News, <http://bbc.in/1xjHHTi> (Aug. 14, 2016).

Dodoo, A., Gustavsson, L., and Sathre, R. (2014). "Lifecycle carbon implications of conventional and low-energy multi-storey timber building systems." Energy and Build., 82, 194-210.

Hairstans, R. (2015). “'Building Offsite. An introduction.” Edinburgh. <http://bit.ly/2bP3ULX> (Aug. 19, 2016)

HM Government. (2013). "Construction 2025. Industrial Strategy: government and industry in partnership." London $<\mathrm{https}$ ///www.gov.uk/government/publications/construction-2025-strategy> (Aug. 19 2016)

Homes for Scotland. (2015). "Mainstreaming Offsite Modern Methods of Construction (MMC) in House Building." Edinburgh. <http://bit.ly/2b2Tzuz> (Aug. 19 2016)

Jaillon, L., Poon, C. S., and Chiang, Y. H. (2008). "Quantifying the waste reduction potential of using prefabrication in building construction in Hong Kong.” Waste Manage. (Oxford), 29(1), 309-320.

Johnsson, H., and Meiling, J. H. (2009). "Defects in offsite construction: timber module prefabrication." Construction Management and Economics, 27(7), 667-681.

Kamali, M., and Hewage, K. (2016). "Life cycle performance of modular buildings: A critical review." Renewable Sustainable Energy Rev., 62, 1171-1183.

Krug, D., and Miles, J. (2013). “Offsite construction: Sustainability characteristics.” London. $<$ http://www.buildoffsite.com/outputs/publications/> (Aug. 19 2016)

Kuittinen, M. (2015). "Setting the Carbon Footprint Criteria for Public Construction Projects." Procedia Economics and Finance, 21(15), 154-161.

Lehmann, S. (2013). "Low carbon construction systems using prefabricated engineered solid wood panels for urban infill to significantly reduce greenhouse gas emissions." Sustainable Cities and Society, 6(1), 57-67.

Meiling, J., Fredrik Backlund, and Johnsson, H. (2015). "Managing for continuous improvement in off-site construction: Evaluation of lean management principles." Engineering, Construction and Architectural Management, 23(2), 237-260.

Miles, J., and Whitehouse, N. (2013). “'Offsite Housing Review.' London. <http://bit.ly/2bHhPST> (Aug. 19 2016)

Monahan, J., and Powell, J. C. (2011). "An embodied carbon and energy analysis of modern methods of construction in housing: A case study using a lifecycle assessment framework." Energy and Build., 43(1), 179-188.

Nahmens, I., and Ikuma, L. H. (2012). "Effects of Lean Construction on Sustainability of Modular Homebuilding." J. Archit. Eng., $18(2), 155-163$.

Pan, W., Gibb, A., and Dainty, A. (2005). “'Offsite Modern Methods of Construction in Housebuilding Perspectives and Practices of Leading UK Housebuilders.' London. <http://bit.ly/2blSXOR> (Aug. 19 2016)

Taylor, M. D. (2010). "A definition and valuation of the UK offsite construction sector." Construction Management and Economics, 28(8), 885-896.

Womack, J., and Jones, D. (2003). Lean Thinking. Simon and Schuster. London. 